\title{
Elevated plasma D-dimer levels are associated with short-term poor outcome in patients with acute ischemic stroke: a prospective, observational study
}

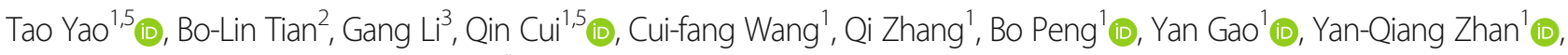
Dan $\mathrm{Hu}^{1}$, Lu Xu ${ }^{1}$ and Gao-Hua Wang ${ }^{4,5^{*}}$

\begin{abstract}
Background: Elevated levels of plasma D-dimer increase the risk of ischemic stroke, stroke severity, and the progression of stroke status, but the association between plasma D-dimer level and functional outcome is unclear. The aim of this study is to investigate whether plasma D-dimer level is a determinant of short-term poor functional outcome in patients with acute ischemic stroke (AIS).

Methods: This prospective study included 877 Chinese patients with AIS admitted to Renmin Hospital of Wuhan University within $72 \mathrm{~h}$ of symptom onset. Patients were categorized by plasma D-dimer level: Quartile $1(\leq 0.24 \mathrm{mg} /$ $\mathrm{L})$, Quartile $2(0.25-0.56 \mathrm{mg} / \mathrm{L})$, Quartile $3(0.57-1.78 \mathrm{mg} / \mathrm{L})$, and Quartile $4(>1.78 \mathrm{mg} / \mathrm{L})$. The medical record of each patient was reviewed, and demographic, clinical, laboratory and neuroimaging information was abstracted. Functional outcome at 90 days was assessed with the modified Rankin Scale.

Results: Poor outcome was present in 302 (34.4\%) of the 877 patients that were included in the study (mean age, 64 years; male, 68.5\%). After adjustment for potential confounding variables, higher plasma D-dimer level on admission was associated with poor outcome (adjusted odds ratio 2.257, 95\% confidence interval 1.349-3.777 for $\mathrm{Q} 4: \mathrm{Q} 1 ; \mathrm{P}$ trend $=0.004)$. According to receiver operating characteristic $(\mathrm{ROC})$ analysis, the best discriminating factor for poor outcome was a plasma D-dimer level $\geq 0.315 \mathrm{mg} / \mathrm{L}$ (area under the ROC curve 0.657; sensitivity 83.8\%; specificity $41.4 \%)$.

Conclusion: Elevated plasma D-dimer levels on admission are significantly associated with poor outcome after admission for AIS, suggesting the potential role of plasma D-dimer level as a predictive marker for short-term poor outcome in patients with AIS.
\end{abstract}

Keywords: Acute ischemic stroke, D-dimer, Outcome, Modified Rankin scale

\section{Background}

Epidemiological investigations have concluded that stroke is a leading cause of adult disability and mortality, and poses a serious public health burden worldwide [13]. Recently, the multicenter Global Burden of Disease (GBD 2016) Study found that the risk of ischemic stroke

\footnotetext{
*Correspondence: wgh6402@163.com

${ }^{4}$ Department of Psychiatry, Renmin Hospital of Wuhan University, Wuhan 430060, China

${ }^{5}$ Institute of Neuropsychiatry, Renmin Hospital of Wuhan University, Wuhan 430060, China

Full list of author information is available at the end of the article
}

was $18.3 \%$ and the risk of hemorrhagic stroke was $8.2 \%$ among adults 25 years of age or older [4]. As a predominant stroke subtype in Chinese populations [5], acute ischemic stroke (AIS) reached $66.4 \%$ among the stroke subtypes between September 2007 and August 2008 in the Chinese National Stroke Registry [6]. Because of the high morbidity and risk of disability after AIS, an estimation of prognosis is an emergent issue, especially when physicians are confronted with concerns from patients and families. Recent studies have assessed prognostic factors such as glycemic index, body mass index (BMI),

(c) The Author(s). 2019 Open Access This article is distributed under the terms of the Creative Commons Attribution 4.0 International License (http://creativecommons.org/licenses/by/4.0/), which permits unrestricted use, distribution, and 
and uric acid, but their prognostic values in relation to AIS was inconsistent [7-12]. For specific management of stroke rehabilitation in regard to the neurological functional outcome, identifying more powerful predictors of clinical prognosis is warranted.

$\mathrm{D}$-dimer is a soluble fibrin degradation final product and derived from the cross-linked fibrin network as it undergoes plasmin-mediated degradation. The plasma D-dimer level increases during blood thrombosis and degradation of fibrin, therefore plasma D-dimer could be a biological marker of hemostatic abnormalities and thrombosis [13]. Elevated plasma D-dimer levels are reportedly a determinant of stroke progression [14], infarction volume [15], and the incidence of stroke [16]. Recently, many studies have investigated whether plasma D-dimer levels are a determinant of poor functional outcomes after AIS, however, the conclusions of the studies were controversial [17-20]. Some investigators have found that plasma D-dimer levels could independently predict poor functional outcomes in patients with AIS $[17,18]$, while other investigators have reported conflicting results $[19,20]$.

Accordingly, the aim of this study was to investigate whether elevated plasma D-dimer levels could be a significant determinant of poor outcome after admission for AIS.

\section{Methods}

\section{Study population}

This was a prospective follow-up study. Data were retrospectively analyzed from a prospective registry. We enrolled 877 consecutive Chinese patients with AIS at Renmin Hospital of Wuhan University from January 2017 to August 2018. All patients were admitted within $72 \mathrm{~h}$ of experiencing a new focal or global neurological event. AIS was diagnosed according to the World Health Organization criteria [21] combined with brain computed tomography or magnetic resonance confirmation within $72 \mathrm{~h}$. Patients were excluded if any of the following criteria were met: a delay of $72 \mathrm{~h}$ from symptom recognition to admission, age younger than 18 years, preexisting significant disability (defined as modified Rankin scale, $m R S \geq 2$ ) from any condition, intracranial hemorrhage, malignancy, febrile disorders, and acute or chronic inflammatory disease at study enrollment. Each participant was followed up after 3 months via telephone, email, and face to face. The study protocol complied with the Declaration of Helsinki and was approved by the Wuhan University Ethics Committee.

\section{Demographic and clinical assessment}

Socio-demographic, self-reported medical history, and vascular risk biomarker data were assessed and included: age, sex, BMI, history of hypertension, diabetes, alcohol consumption, smoking, dyslipidemia, atrial fibrillation, previous stroke, and coronary artery disease (CAD). The National Institutes of Health Stroke Scale (NIHSS) scores were used by stroke neurologists to assess neurological deficit when the patients were admitted [22]. Stroke subtype was classified according to the Trial of Org 10172 in acute stroke treatment (TOAST classification) criteria [23], which distinguished large-artery arteriosclerosis, small-artery occlusion, cardioembolism, other causative factor, and undetermined causative factor.

Fasting plasma glucose (FPG) and plasma D-dimer level were measured in the morning after at least $8 \mathrm{~h}$ of fasting. Plasma D-dimer level was measured for all patients with a particle-enhanced immunoturbidimetric assay in a calibrated SYSMEX7000 analyzer (Sysmex Corporation, Hyogo, Japan). The normal range of morning plasma D-dimer concentration in our hospital laboratory is $0-0.55 \mathrm{mg} / \mathrm{L}$.

\section{Follow-up and short-term outcomes}

Patient follow-up was performed at 90 days after stroke onset. The prognosis outcome was assessed with modified Rankin Scale (mRS) via telephone, email, and face to face by a trained research nurse or neurologist. A good functional outcome was defined as an mRS of 0-2 points, whereas a poor outcome was defined as an $\mathrm{mRS}$ of 3-6 points.

\section{Statistical analysis}

For continuous variables, data are expressed either as the means \pm standard deviations (SD) or medians (interquartile ranges, IQR). Categorical variables are expressed as frequencies and percentages. The patients were categorized into two groups according to prognosis outcome (good outcome vs poor outcome). A two-group comparison of normally distributed continuous variables was assessed using independent $\mathrm{t}$-tests. The non-parametric Mann-Whitney $U$ test was used for continuous variables that were not normally distributed. The $\chi^{2}$ test was used for categorical variables. Furthermore, we categorized the patients into four quartile groups according to their plasma D-dimer level at admission. A four-group comparison was assessed using the $X^{2}$ test, one-way analysis of variance (ANOVA) and Mann-Whitney $U$ tests, as appropriate. Multivariate analysis adjustment for variables was performed for the correlation between the quartiles of plasma D-dimer levels and poor outcome by logistic regression analysis, which used methods from previous studies $[24,25]$. Results were expressed as adjusted odds ratios (OR) with the corresponding 95\% confidence intervals (CIs). Receiver operating characteristic (ROC) curves were utilized to evaluate the accuracy of plasma D-dimer level to predict AIS poor neurological outcome. The area under the curve (AUC) was 
calculated as a measurement of the accuracy of the test. All statistical analysis was performed with SPSS for Windows, version 22.0 (SPSS Inc., Chicago, IL, USA). $P<$ 0.05 was considered statistically significant.

\section{Results}

Baseline characteristics of the patients

A total of 877 AIS patients (median age 64 years, 68.5\% male) who met the inclusion criteria were recruited for this study. The variables associated with functional outcome of AIS included sex, age, BMI, vascular risk factors (smoking, alcohol drinking, atrial fibrillation, diabetes, hypertension, CAD, dyslipidemia, previous stroke), baseline systolic blood pressure (SBP), baseline systolicdiastolic blood pressure (DBP), FBG, baseline NIHSS scores and stroke subtype. The median plasma D-dimer level on admission was $0.56(0.24-1.79) \mathrm{mg} / \mathrm{L}$, and the median NIHSS score on admission was 5 (3-8). In this study, 575 patients $(65.6 \%)$ presented with good outcomes, 302 patients (34.4\%) presented with poor outcomes, and 77 patients (8.8\%) died among the 877 patients within 90 days. The baseline characteristics and outcome of the patients with AIS are described in Table 1. The sex, age, BMI, smoker, history of atrial fibrillation, FBG, plasma D-dimer level, baseline NIHSS scores, and stroke etiology were markedly associated with the outcomes of AIS at 90 days $(P<0.05$ for all). Figure 1 shows the plasma D-dimer level between two functional outcome groups. In the patients with poor outcome, plasma D-dimer levels were significantly higher compared with those in patients with good outcomes $[0.88$ (IQR, 0.42-2.72) $\mathrm{mg} / \mathrm{L}$ vs 0.46 (IQR, 0.211.32) $\mathrm{mg} / \mathrm{L} ; \mathrm{Z}=-7.655, P=0.000]$.

\section{Correlation between plasma D-dimer level and 90-day functional outcome}

Patients were stratified into four groups according to plasma D-dimer quartiles: Plasma D-dimer levels $\leq 0.24$ ( $n=226), 0.25-0.56(n=213), 0.57-1.78(n=219)$, and > $1.78 \mathrm{mg} / \mathrm{L}(n=219)$ (Table 2$)$. Among the four groups, there were no significant differences in the history of hypertension, diabetes, dyslipidemia, previous stroke, drinking alcohol, FBG, and baseline SBP $(P>0.05$ for all). Age, sex, BMI, smoking, atrial fibrillation, baseline

Table 1 Baseline characteristics of the study patients grouped by 90-day functional outcome

\begin{tabular}{|c|c|c|c|c|}
\hline Variable & $\begin{array}{l}\text { all } \\
(n=877)\end{array}$ & $\begin{array}{l}\text { good outcome } \\
(n=575)\end{array}$ & $\begin{array}{l}\text { poor outcome } \\
(n=302)\end{array}$ & $\begin{array}{l}P \\
\text { value }\end{array}$ \\
\hline Age (years), median (IQR) & $64.00(54.50-73.00)$ & $62(52-70)$ & $68(60-77.25)$ & 0.000 \\
\hline Sex (male), n (\%) & $601(68.5)$ & $413(71.8)$ & $188(62.3)$ & 0.004 \\
\hline BMI (kg/m2),(Mean \pm SD) & $25.09 \pm 3.64$ & $24.76 \pm 3.54$ & $25.70 \pm 3.74$ & 0.000 \\
\hline Smoker, n (\%) & $337(38.4)$ & $217(37.7)$ & $120(39.7)$ & 0.307 \\
\hline Alcohol drinkers, n (\%) & $192(21.9)$ & $137(23.8)$ & $55(18.2)$ & 0.056 \\
\hline Hypertension, n (\%) & $531(60.5)$ & $336(58.4)$ & $195(64.6)$ & 0.077 \\
\hline Diabetes mellitus, n (\%) & $281(32.0)$ & $172(29.9)$ & $109(36.1)$ & 0.062 \\
\hline CAD, n (\%) & $106(12.1)$ & $61(10.6)$ & $45(14.9)$ & 0.064 \\
\hline Atrial fibrillation, n (\%) & $110(12.5)$ & $44(7.7)$ & $66(21.9)$ & 0.000 \\
\hline Dyslipidemia, n (\%) & $309(35.2)$ & $209(36.3)$ & $100(33.1)$ & 0.341 \\
\hline Previous stroke, n (\%) & $116(13.2)$ & $73(12.7)$ & $43(14.2)$ & 0.522 \\
\hline NIHSS on admission, median (IQR) & $5(3-8)$ & $5(3-7)$ & $7(5-8)$ & 0.000 \\
\hline $\mathrm{SBP}(\mathrm{mmHg})$, median (IQR) & $147(131-164)$ & $147(132-162)$ & $147(130-165)$ & 0.949 \\
\hline $\mathrm{DBP}(\mathrm{mmHg})$, median (IQR) & $83(75-92)$ & $83(75-92)$ & $83(74-92)$ & 0.229 \\
\hline FBG (mmol/L), median (IQR) & $6(4.81-8.22)$ & $5.62(4.63-7.50)$ & $6.70(5.46-9.50)$ & 0.000 \\
\hline D-dimer (mg /L), median (IQR) & $0.56(0.24-1.79)$ & $0.46(0.21-1.32)$ & $0.88\left(0.42 \_2.72\right)$ & 0.000 \\
\hline Stroke etiology, n (\%) & & & & 0.000 \\
\hline Large-vessel occlusive & $344(39.2)$ & $176(30.6)$ & $168(55.6)$ & \\
\hline Small-vessel occlusive & $366(41.7)$ & $312(54.3)$ & $54(17.9)$ & \\
\hline Cardioembolic & $88(10)$ & $32(5.6)$ & $56(18.5)$ & \\
\hline Other & $30(3.4)$ & $21(3.7)$ & $9(3.0)$ & \\
\hline Undetermined & $49(5.6)$ & $34(5.9)$ & $15(5.0)$ & \\
\hline
\end{tabular}

$B M I$ body mass index, CAD coronary artery disease, NIHSS National Institutes of Health Stroke Scale, SBP systolic blood pressure, DBP diastolic blood pressure, IQR interquartile range, $S D$ standard deviation

${ }^{a} P$ value was assessed using $X^{2}$ test, independent $t$-tests, or Mann-Whitney $U$ test, as appropriate 


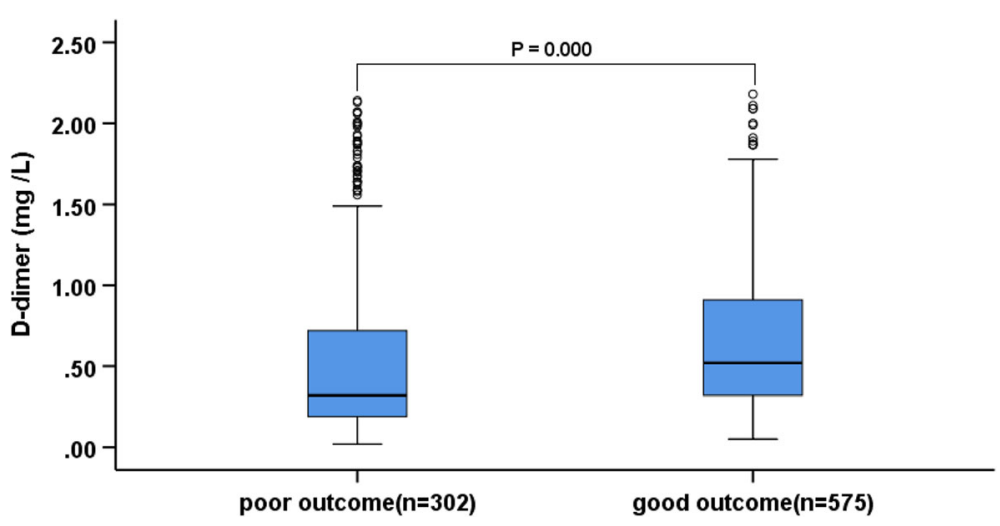

Fig. 1 Plasma D-dimer level in patients with good or poor outcomes. Mann-Whitney U-test $(Z=-7.655, P=0.000)$

DBP, baseline NIHSS scores, stroke etiology, and mortality differed among the four groups $(P<0.05$ for all). The unadjusted comparisons of the four groups revealed more poor outcomes among the higher quartiles of Plasma D-dimer levels $\left(\chi^{2}=53.724, P=0.000\right)$ (Fig. 2).
Functional outcome stratified for plasma D-dimer levels is shown in Fig. 3. Univariate analysis shows a clear relationship between admission plasma D-dimer levels and $\mathrm{mRS}$ using the $\chi^{2}$ Test $\left(\chi^{2}=877.000, \mathrm{P}\right.$ trend $=$ 0.000). Furthermore, the correlation between plasma D-

Table 2 Baseline characteristics of the study patients grouped by plasma D-dimer quartile

\begin{tabular}{|c|c|c|c|c|c|}
\hline & $\begin{array}{l}\text { Quartile } 1 \\
(\leq 0.24) n=226\end{array}$ & $\begin{array}{l}\text { Quartile } 2 \\
(0.25-0.56) n=213\end{array}$ & $\begin{array}{l}\text { Quartile } 3 \\
(0.57-1.78) n=219\end{array}$ & $\begin{array}{l}\text { Quartile } 4 \\
(>1.78) n=219\end{array}$ & Pvalue \\
\hline Age (years), median (IQR) & $59(50-66)$ & $66(58-74)$ & $66(53-76)$ & $66(57-76)$ & 0.000 \\
\hline Sex (male), n (\%) & $172(76.1)$ & $152(71.4)$ & $142(64.8)$ & $135(61.6)$ & 0.005 \\
\hline BMI $(\mathrm{kg} / \mathrm{m} 2),($ Mean $\pm \mathrm{SD})$ & $24.89 \pm 3.52$ & $24.79 \pm 3.56$ & $24.99 \pm 3.64$ & $25.69 \pm 3.78$ & 0.040 \\
\hline Smoker, n (\%) & $102(45.1)$ & $90(42.3)$ & $74(33.8)$ & $71(32.4)$ & 0.012 \\
\hline Alcohol drinker, n (\%) & $56(24.8)$ & $51(23.9)$ & $44(20.1)$ & $41(18.7)$ & 0.344 \\
\hline Hypertension, n (\%) & $138(61.1)$ & $131(63.5)$ & $130(59.4)$ & $133(60.7)$ & 0.972 \\
\hline Diabetes mellitus, n (\%) & $83(36.7)$ & $71(33.3)$ & $55(25.1)$ & $72(32.9)$ & 0.062 \\
\hline CAD, n (\%) & $18(8.0)$ & $24(11.3)$ & $27(12.3)$ & $37(16.9)$ & 0.036 \\
\hline Atrial fibrillation, n (\%) & $10(4.4)$ & $23(10.8)$ & $30(13.7)$ & $47(21.5)$ & 0.000 \\
\hline Dyslipidemia, n (\%) & $90(39.8)$ & $80(37.6)$ & $63(28.8)$ & $76(34.7)$ & 0.085 \\
\hline Previous stroke, n (\%) & $22(9.7)$ & $38(17.8)$ & $28(12.8)$ & $28(12.8)$ & 0.093 \\
\hline NIHSS on admission, median (IQR) & $4(3-7)$ & $5(3-7)$ & $6(3-7)$ & $7(5-10)$ & 0.000 \\
\hline $\mathrm{SBP}(\mathrm{mmHg})$, median (IQR) & $148(134-165)$ & $145(131-162)$ & $144(130-162)$ & $152(134-166)$ & 0.221 \\
\hline $\mathrm{DBP}(\mathrm{mmHg})$, median (IQR) & 85 (78-95) & $82(76-90)$ & $80(74-90)$ & $84(76-93)$ & 0.001 \\
\hline FBG (mmol/L), median (IQR) & $5.7(4.66-8.23)$ & $6.01(4.95-7.85)$ & $5.90(4.78-7.46)$ & $6.23(5.00-9.10)$ & 0.089 \\
\hline D-dimer (mg /L), median (IQR) & $0.17(0.12-0.21)$ & $0.38(0.31-0.48)$ & $0.92(0.72-1.27)$ & $3.06(2.45-3.97)$ & 0.000 \\
\hline Stroke etiology, n (\%) & & & & & 0.000 \\
\hline Large-vessel occlusive & $81(35.8)$ & $82(38.5)$ & $86(39.3)$ & $95(43.4)$ & \\
\hline Small-vessel occlusive & $118(52.2)$ & $93(43.7)$ & $91(41.6)$ & $64(29.2)$ & \\
\hline Cardioembolic & $7(3.1)$ & $18(8.5)$ & $24(11)$ & $39(19.8)$ & \\
\hline Other & $12(5.3)$ & $7(3.3)$ & $5(2.3)$ & $6(2.7)$ & \\
\hline Unknown & $8(3.5)$ & $13(6.1)$ & $13(5.9)$ & $15(6.8)$ & \\
\hline Mortality, n (\%) & $4(1.8)$ & $13(6.1)$ & $24(11)$ & 36 (16.4) & 0.000 \\
\hline
\end{tabular}

$B M I$ body mass index, CAD coronary artery disease, NIHSS National Institutes of Health Stroke Scale, SBP systolic blood pressure, DBP diastolic blood pressure, IQR interquartile range, $S D$ standard deviation

a $P$ value was assessed $X^{2}$ test, ANOVA or Mann-Whitney $U$ tests, as appropriate 


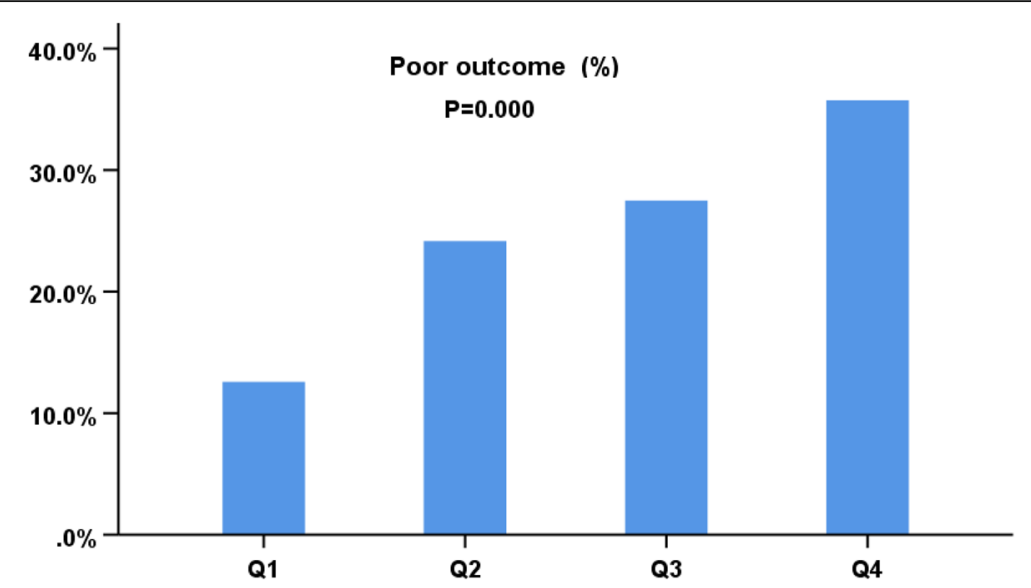

Fig. 2 Comparisons of the outcome of AIS patients according to quartiles for plasma D-dimer levels. $X^{2}$ Test for trend $\left(X^{2}=53.724, P=0.000\right)$

dimer levels and poor outcome after adjustment for variables are detailed in Table 3. In patients with high plasma D-dimer levels, the risk of poor functional outcome at 90 days was significantly increased when compared with the group with low plasma $\mathrm{D}$-dimer levels $(\mathrm{P}$ trend $=0.000, \mathrm{OR}=3.800,95 \% \mathrm{CI}=2.420-5.965$ for $\mathrm{Q} 4$ : Q1; adjusted for age, sex, and BMI). Additional adjustment for smokers, alcohol drinkers, atrial fibrillation, diabetes, hypertension, CAD, dyslipidemia, previous stroke, baseline SBP, baseline DBP, FBG, baseline NIHSS scores, and stroke etiology did not influence this finding. An overall OR of 2.257 ( $\mathrm{P}$ trend $=0.004,95 \% \mathrm{CI}=$ 1.349-3.777 for Q4: Q1) was found for patients with high plasma D-dimer levels.

\section{Predictive values of plasma D-dimer level in patient outcome}

To further evaluate the predictive values of plasma Ddimer levels in patients with AIS, the ROC curves and AUCs were created and are depicted in Fig. 4. Based on the ROC curve, the optimal cut-off value of plasma D-dimer levels as an indicator for diagnosis of unfavorable functional outcome was projected to be $0.315 \mathrm{mg} / \mathrm{L}$, which yielded a sensitivity of $83.8 \%$ and a specificity of $41.4 \%$, the AUC was $0.657(95 \% \mathrm{CI}$, 0.620-0.694; $P=0.000$ ).

\section{Discussion}

In the present study, higher plasma D-dimer level on admission was a significant independent determinant of short-term neurological dysfunction in patients with AIS within 90 days in a Chinese population. After adjusting for various confounders, the correlation remained significant.

Previous prospective epidemiological investigations have concluded that there is a positive association between plasma D-dimer levels and stroke [26-28]. In some studies, the results showing that plasma D-dimer levels were associated with stroke severity $[29,30]$, infarct volume [15, 31, 32], and progression of stroke status $[14,33,34]$. However, the relationship between

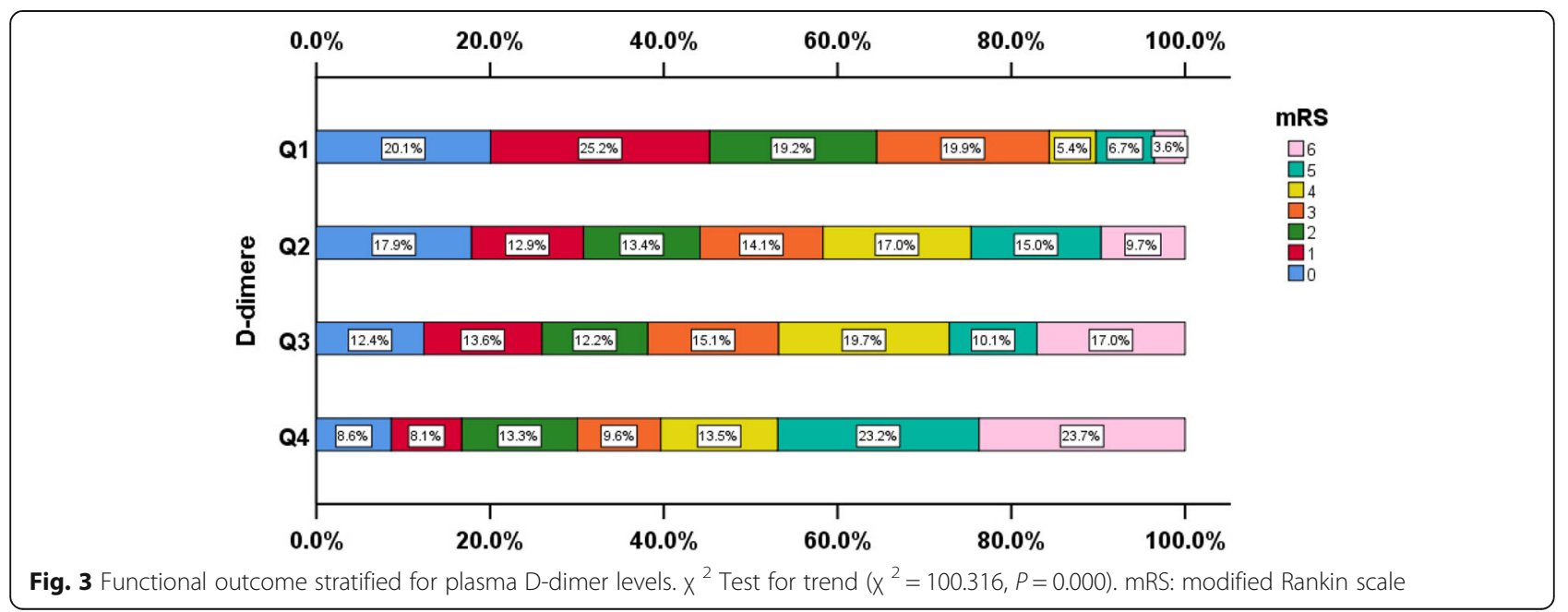


Table 3 Adjusted odds ratios for poor outcome according to plasma D-dimer levels

\begin{tabular}{lllllllll}
\hline & Quartile 1 & Quartile 2 & $P$ value & Quartile 3 & $P$ value & Quartile 4 & $P$ value & $P$ for trend \\
\hline $\mathrm{OR}(95 \% \mathrm{Cl})^{\mathrm{a}}$ & 1 & $2.139(1.348-3.393)$ & 0.001 & $2.518(1.596-3.974)$ & 0.000 & $3.800(2.420-5.965)$ & 0.000 & 0.000 \\
$\mathrm{OR}(95 \% \mathrm{Cl})^{\mathrm{b}}$ & 1 & $2.021(1.225-3.334)$ & 0.006 & $2.503(1.527-4.105)$ & 0.000 & $3.181(1.964-5.201)$ & 0.000 & 0.000 \\
$\mathrm{OR}(95 \% \mathrm{Cl})^{\mathrm{c}}$ & 1 & $2.028(1.208-3.405)$ & 0.007 & $2.246(1.345-3.749)$ & 0.002 & $2.257(1.349-3.777)$ & 0.002 & 0.004 \\
\hline
\end{tabular}

$O R$ odds ratio, $C l$ confidence interval, $O R^{\mathrm{a}}$ adjusted for age, sex, and body mass index, $O R^{\mathrm{b}}$ as note a with additional adjustment for smokers, alcohol drinkers, atrial fibrillation, diabetes, hypertension, CAD, dyslipidemia, previous stroke, and stroke etiology, OR ${ }^{c}$ as note b with additional adjustment for baseline SBP, DBP, FBG, and NIHSS, SBP systolic blood pressure, DBP diastolic blood pressure, FPG fasting plasma glucose, NIHSS National Institutes of Health Stroke Scale

plasma D-dimer levels and functional outcome in patients with AIS has been poorly studied.

The available studies on stroke have shown relationships between plasma D-dimer level and functional outcome in several different population types with AIS [3539]. Nam et al. [35] and Nezu et al. [36] found a predictive role of plasma $\mathrm{D}$-dimer levels only in patients with cryptogenic stroke. A Canadian study by Kim et al. [37] reported the prognostic value of plasma D-dimer level in patients with noncardioembolic stroke. In a study of a Chinese population with complicating coronary heart disease, the result indicated that higher plasma D-dimer levels had a worse outcome within 90 days after the initial onset of AIS [38]. A Swiss study by Hsu et al. reported that a high plasma D-dimer levels indicates an unfavorable outcome in patients with AIS receiving intravenous thrombolysis [39]. However, on reviewing previous literature, we also found that some other studies have reported conflicting results. A report by Squizzato et al. [19] revealed that plasma D-dimer level in patients with AIS probably does not predict the functional outcome after adjustment for age and stroke

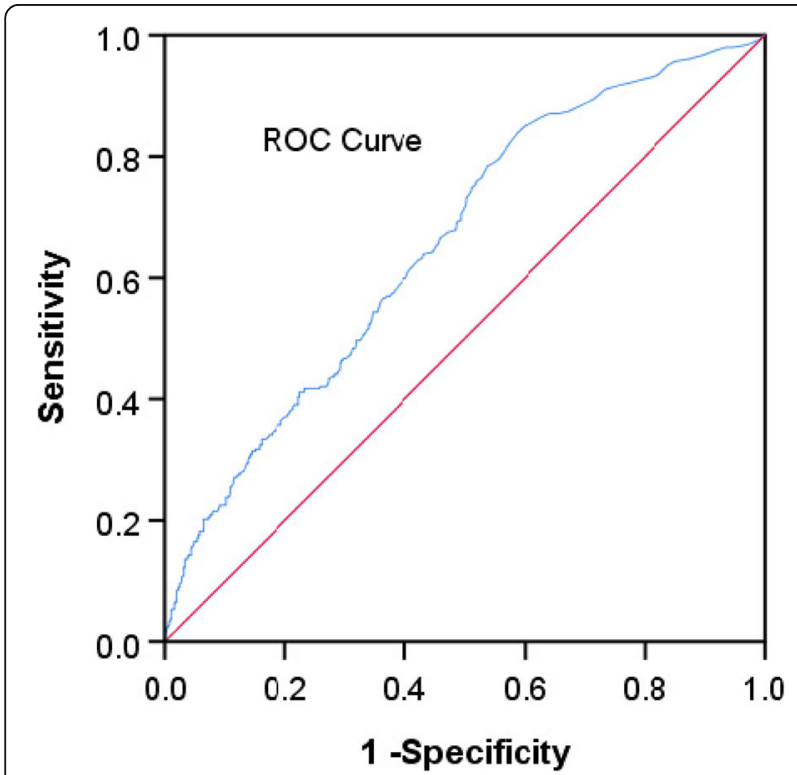

Fig. 4 Receiver operating characteristic (ROC) curves were used to evaluate the predictive values of plasma D-dimer levels for poor outcome (area under the curve: $0.657 ; 95 \% \mathrm{Cl}, 0.620-0.694 ; P=0.000$ ) subtype. Furthermore, two other studies did not even find a meaningful association between plasma D-dimer levels and the prognosis of patients with AIS [40, 41].

In this study, because the prognostic value did not alter even after adjusting for various confounders such as age, sex, BMI, vascular risk factors, baseline NIHSS scores, and stroke etiology, our results revealed plasma D-dimer levels are an independent biological prognostic marker of AIS. In fact, the positive value of plasma Ddimer in patients with all subtypes of AIS was indicated in several previous studies [33, 41, 42], which is consistent with our findings.

D-dimer derived from the cross-linked fibrin network is a final soluble fibrin degradation product which undergoes plasmin-mediated degradation [13]. Plasma D-dimer could be elevated in a population with thrombotic diseases such as pulmonary embolism and venous thromboembolism $[42,43]$, however, the mechanism remains unclear. There are several possible explanations for why plasma D-dimer levels might be relevant to poor functional outcome in patients with AIS. For instance, plasma D-dimer level increases in blood coagulation and degradation of fibrin and could be a marker of thrombosis based on the underlying mechanisms [44, 45]. Moreover, a high plasma D-dimer levels may result in resistance to the endogenous fibrinolytic system and influence thromboembolism formation [40, 46]. Furthermore, plasma D-dimer also stimulates the immune system and leads to changes in inflammatory mediators levels such as IL-1, TNF-alpha, IL-6, and IL-8 [47, 48]. Activated inflammation may contribute to the pathological alteration in patients with AIS [49]. In addition, infarct volume, initial stroke severity, and progression of stroke status were correlated with a high plasma Ddimer levels [14, 29-34], therefore elevated plasma Ddimer levels may predict poor outcome through the aggravation of cerebral tissue damage by disturbing recanalization and increasing reperfusion injury. Additionally, the plasma D-dimer levels in patients with AIS may identify those who may benefit from additional interventions, targeting some of the mechanisms mentioned above. This needs to be explored in further studies.

The present study has several limitations. First, this is a single-center, observational study. The sample sizes of patients are small, and selection bias was a major 
concern, thereby limiting the power to generalize our results. Second, the plasma D-dimer levels were measured only in the morning after at least $8 \mathrm{~h}$ of fasting in our study, however, recording the serial change of plasma Ddimer levels might better explore the correlation between D-dimer and outcome after AIS. Finally, our study explored the short-term outcome with an end-point defined at 90 days. The correlation between plasma Ddimer levels and long-term prognosis requires further confirmation in our study population. Therefore, further multicenter studies with a larger sample size need to be conducted.

\section{Conclusions}

Elevated plasma D-dimer levels on admission are significantly associated with poor outcome after admission for AIS, suggesting a high plasma D-dimer level within $72 \mathrm{~h}$ of a stroke as a predictive marker for short-term poor outcome after 90 days in patients with AIS. Plasma Ddimer level is a convenient and economical biological indicator that could be used for improving the specific management of stroke rehabilitation and functional outcome.

\section{Abbreviations}

AIS: Acute ischemic stroke; ANOVA: Analysis of variance; AUC: Area under the ROC curve; BMI: Body mass index; CAD: Coronary artery disease; Cl: Confidence interval; DBP: Diastolic blood pressure; FPG: Fasting plasma glucose; IL: Interleukin; IQR: Interquartile ranges; mRS: Modified Rankin scale; NIHSS: National Institutes of Health Stroke Scale; OR: Odds ratio; ROC: Receiver operating characteristic; SBP: Systolic blood pressure; SD: Standard deviations; TNF: Tumor necrosis factor; TOAST: Trial of Org 10,172 in Acute Stroke Treatment

\section{Acknowledgments}

We thank all the participants for their participation in this study.

\section{Authors' contributions}

TY interpreted the patient data and were the main contributors in writing the manuscript. TY, B-LT, GL, DH, and Y-QZ performed the statistical analysis and were a major contributor in writing the manuscript. QC, C-fW, QZ, BP, $Y G$, and LX collected the data and were the major contributors in writing the manuscript. G-HW participated in study design, data interpretation and revised the manuscript critically for important intellectual content. All authors read and approved the final manuscript.

\section{Funding}

This study was supported by the National Natural Science Foundation of China (No. 81401051) and the Hubei Provincial Natural Science Foundation of China (No. 2016CFB575). The funding bodies did not influence the study design, the collection, analysis, and interpretation of data, the manuscript writing, and the decision to submit it for publication.

\section{Availability of data and materials}

The datasets used and/or analyzed during the current study are available from the corresponding author on reasonable request.

\section{Ethics approval and consent to participate}

This study is approved by the Ethics Committee of Wuhan Universit. All participants gave written informed consent for participation and publication.

\section{Consent for publication}

Not applicable.

\section{Competing interests}

The authors declare that they have no competing interests.

\section{Author details}

${ }^{1}$ Department of Neurology, Renmin Hospital of Wuhan University, Wuhan 430060, China. ${ }^{2}$ Department of Neurology, Dawu County Hospital of

Traditional Chinese Medicine, Hubei 432800, China. ${ }^{3}$ Emergency Department, Hubei Provincial Hospital of Traditional Chinese Medicine, Wuhan 430061

China. ${ }^{4}$ Department of Psychiatry, Renmin Hospital of Wuhan University, Wuhan 430060, China. ${ }^{5}$ Institute of Neuropsychiatry, Renmin Hospital of Wuhan University, Wuhan 430060, China.

Received: 7 February 2019 Accepted: 1 July 2019

Published online: 22 July 2019

References

1. Go AS, Mozaffarian D, Roger VL, Benjamin EJ, Berry JD, Borden WB, Bravata DM, Dai S, Ford ES, Fox CS, et al. Heart disease and stroke statistics - 2013 update: a report from the American Heart Association. Circulation. 2013; 127(1):e6-e245.

2. Feigin $\mathrm{VL}$, Forouzanfar MH, Krishnamurthi R, Mensah GA, Connor M, Bennett DA, Moran AE, Sacco RL, Anderson L, Truelsen T, et al. Global and regional burden of stroke during 1990-2010: findings from the Global Burden of Disease Study 2010. Lancet (London, England). 2014;383(9913):245-54.

3. Global, regional, and national incidence, prevalence, and years lived with disability for 301 acute and chronic diseases and injuries in 188 countries, 1990-2013: a systematic analysis for the Global Burden of Disease Study 2013. Lancet (London, England). 2015;386(9995):743-800.

4. VL F, G N, K C, CO J, T A, PG P, AA A, KH A, F A-A, AN A, et al. Global, Regional, and Country-Specific Lifetime Risks of Stroke, 1990 and 2016. N Engl J Med. 2018;379(25):2429-37.

5. Wang Y, Liu M, Pu C. 2014 Chinese guidelines for secondary prevention of ischemic stroke and transient ischemic attack. Int J Stroke. 2017;12(3):302.

6. Yongjun W, Liying C, Xunming J, Qiang D, Jinsheng Z, Yilong W, Yong Z, Xingquan Z, Chunxue W, Liping L. The China National Stroke Registry for patients with acute cerebrovascular events: design, rationale, and baseline patient characteristics. Int J Stroke. 2011;6(4):355-61.

7. Wolfram D, Johannes S, Anker SD, Jochen S, Audebert HJ. Overweight and obesity are associated with improved survival, functional outcome, and stroke recurrence after acute stroke or transient ischaemic attack: observations from the TEMPiS trial. Eur Heart J. 2013;34(4):268-77.

8. Luitse MJ, Velthuis BK, Kappelle LJ. Van dGY, Biessels GJ, Group DS: Chronic hyperglycemia is related to poor functional outcome after acute ischemic stroke. Int J Stroke. 2017;12(2):180.

9. Mapoure YN, Ayeah CM, Doualla MS, Ba H, Hbm N, Mbahe S, Luma HN. Serum Uric Acid Is Associated with Poor Outcome in Black Africans in the Acute Phase of Stroke. Stroke Res Treat. 2017;2017(11):1935136.

10. Sun W, Huang Y, Xian Y, Zhu S, Jia Z, Liu R, Li F, Wei JW, Wang JG, Liu M. Association of body mass index with mortality and functional outcome after acute ischemic stroke. Sci Rep. 2017;7(1):2507.3.

11. Sung JY, Chen Cl, Hsieh YC, Chen YR, Wu HC, Chan L, Hu CJ, Hu HH, Chiou HY, Chi NF. Comparison of admission random glucose, fasting glucose, and glycated hemoglobin in predicting the neurological outcome of acute ischemic stroke: a retrospective study. Peerj. 2017;5(9):e2948.

12. Wang YF, Li JX, Sun XS, Lai R, Sheng WL. High serum uric acid levels are a protective factor against unfavourable neurological functional outcome in patients with ischaemic stroke. J Int Med Res. 2018;46(5):1826-38.

13. Weitz Jl, Fredenburgh JC, Eikelboom JW. A Test in Context: D-Dimer. J Am Coll Cardiol. 2017;70(19):2411.

14. Mark B, Peter L, Ann R, Lowe GDO, Stott DJ. Hemostatic function and progressing ischemic stroke: D-dimer predicts early clinical progression. Stroke. 2004;35(6):1421-5.

15. Mari M, Manabu S, Shuhei O, Shigetaka F, Masafumi T, Hideki E, Takeshi S, Toshiki Y, Hideki M, Kazuo K. Relationship between plasma (D)-dimer level and cerebral infarction volume in patients with nonvalvular atrial fibrillation. Cerebrovasc Dis. 2013;35(1):64-72.

16. Zhang J, Song Y, Shan B, He M, Ren Q, Zeng Y, Liu Z, Liu H. Xu J: Elevated level of D-dimer increases the risk of stroke. Oncotarget. 2018;9(2):2208-19.

17. Paul W, Mark B, Peter L, Ann R, Lowe GDO, Stott DJ. Associations of inflammatory and haemostatic biomarkers with poor outcome in acute ischaemic stroke. Cerebrovasc Dis. 2009;27(3):247-53. 
18. Dougu N, Takashima S, Sasahara E, Taguchi Y, Toyoda S, Hirai T, Nozawa T, Tanaka K, Inoue H. Predictors of poor outcome in patients with acute cerebral infarction. Journal of Clinical Neurology. 2011;7(4):197-202.

19. Squizzato A, Ageno W, Finazzi S, Mera V, Romualdi E, Bossi A, Venco A. Ddimer is not a long-term prognostic marker following acute cerebral ischemia. Blood Coagul Fibrinolysis. 2006;17(4):303-6.

20. Haapaniemi $E_{1}$., Tatlisumak T, . Is D-dimer helpful in evaluating stroke patients? A systematic review. Acta Neurol Scand 2010, 119(3):141-150.

21. Listed N. Stroke--1989. Recommendations on stroke prevention, diagnosis, and therapy. Report of the WHO Task Force on Stroke and other Cerebrovascular Disorders. Stroke. 1989;20(10):1407.

22. Brott T, ., Adams HP, Olinger CP, Marler JR, Barsan WG, Biller J, ., Spilker J, .,

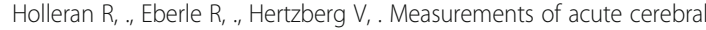
infarction: a clinical examination scale. Stroke 1989, 20(7):864-870.

23. Adams HP Jr, Bendixen BH, Kappelle LJ, Biller J, Love BB, Gordon DL, Marsh EE 3rd. Classification of subtype of acute ischemic stroke. Definitions for use in a multicenter clinical trial. TOAST. Trial of Org 10172 in Acute Stroke Treatment. Stroke. 1993;24(1):35-41.

24. Deng QW, Wang H, Sun CZ, Xing FL, Zhang HQ, Zuo L, Gu ZT, Yan FL. Triglyceride to high-density lipoprotein cholesterol ratio predicts worse outcomes after acute ischaemic stroke. Eur J Neurol. 2017;24(2):283-91.

25. Luitse MJ, Velthuis BK, Kappelle LJ, van der Graaf Y, Biessels GJ. Chronic hyperglycemia is related to poor functional outcome after acute ischemic stroke. Int J Stroke. 2017;12(2):180-6.

26. Di Castelnuovo A, Agnoli C, de Curtis A, Giurdanella MC, Sieri S, Mattiello A, Matullo G, Panico S, Sacerdote C, Tumino R, et al. Elevated levels of Ddimers increase the risk of ischaemic and haemorrhagic stroke. Findings from the EPICOR Study. Thromb Haemost. 2014;112(5):941-6.

27. Folsom AR, Gottesman RF, Appiah D, Shahar E, Mosley TH. Plasma d-Dimer and Incident Ischemic Stroke and Coronary Heart Disease: The Atherosclerosis Risk in Communities Study. Stroke. 2016;47(1):18.

28. Hamatani $Y$, Nagai T, Nakai M, Nishimura $K$, Honda $Y$, Nakano H, Honda S, Iwakami N, Sugano Y, Asaumi Y, et al. Elevated Plasma D-Dimer Level Is Associated With Short-Term Risk of Ischemic Stroke in Patients With Acute Heart Failure. Stroke. 2018;49(7):1737-40.

29. Berge E, Friis $P$, Sandset PM. Hemostatic Activation in Acute Ischemic Stroke. Thromb Res. 2001;101(2):13-21.

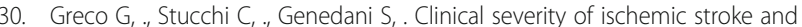
neural damage biomarkers in the acute setting: the STROke MArkers (STROMA) study. Minerva Anestesiol 2013, 79(7):750.

31. Young-Woo P, Eun-Jeong K, Ha-Young C. Correlation between Serum DDimer Level and Volume in Acute Ischemic Stroke. Journal of Korean Neurosurgical Society. 2011;50(2):89.

32. Zi WJ, Shuai J. Plasma D-dimer levels are associated with stroke subtypes and infarction volume in patients with acute ischemic stroke. Plos One. 2014;9(1):e86465

33. Mark B, Peter L, Ann R, Lowe GDO, Stott DJ. D-dimer predicts early clinical progression in ischemic stroke: confirmation using routine clinical assays. Stroke. 2006;37(4):1113-5.

34. Zang R, Zhang H, Xu Y, Zhang S, Liu X, Wang J, Gao Y, Shu M, Mei B, Li H. Serum $C$-reactive protein, fibrinogen and D-dimer in patients with progressive cerebral infarction. Translational Neuroscience. 2016;7(1):84-8.

35. Nam KW, Kim CK, Kim TJ, An SJ, Demchuk AM, Kim Y, Jung S, Han MK, Ko $\mathrm{SB}$, Yoon BW. D-dimer as a predictor of early neurologic deterioration in cryptogenic stroke with active cancer. Eur J Neurol. 2016;24(1).

36. Nezu T, Kitano T, Kubo S, Uemura J, Yamashita S, Iwanaga T, Inoue T, Hosomi N, Maruyama H, Matsumoto M. Impact of D-dimer levels for shortterm or long-term outcomes in cryptogenic stroke patients. J Neurol. 2018; 265(3):1-9.

37. Kim TW, Song IU, Chung SW. Prognostic Value of Serum D-Dimer in Noncardioembolic Ischemic Stroke. The Canadian journal of neurological sciences Le journal canadien des sciences neurologiques. 2017:44(4):404-9.

38. Wang $Y$, Hafeez A, Meng F, Zhang R, Wang X, Chen X, Kong Q, Du H, Ma X. The correlation of D-dimer levels with patient outcomes in acute ischemic cerebrovascular disease complicating coronary heart disease. Neurol Res. 2016;38(6):524-32.

39. Hsu P-J, Chen C-H, Yeh S-J, Tsai L-K, Tang S-C, Jeng J-S. High Plasma D-Dimer Indicates Unfavorable Outcome of Acute Ischemic Stroke Patients Receiving Intravenous Thrombolysis. Cerebrovasc Dis. 2016;42(1-2):117-21
40. Lip GY, Blann AD, Faroogi IS, Zarifis J, Sagar G, Beevers DG. Sequential alterations in haemorheology, endothelial dysfunction, platelet activation and thrombogenesis in relation to prognosis following acute stroke: The West Birmingham Stroke Project. Blood Coagul Fibrinolysis. 2002;13(4):339-47.

41. Rallidis LS, Vikelis M, ., Panagiotakos DB, Liakos GK, Krania E, ., Kremastinos DT: Usefulness of inflammatory and haemostatic markers to predict shortterm risk for death in middle-aged ischaemic stroke patients. Acta Neurol Scand 2010, 117(6):415-420.

42. Keller K, Beule J, Balzer JO, Dippold W. D-Dimer and thrombus burden in acute pulmonary embolism. Am J Emerg Med. 2018;36(9):1613-8.

43. Sartori M, Migliaccio L, Favaretto E, Cini M, Legnani C, Palareti G, Cosmi B. D-dimer for the diagnosis of upper extremity deep and superficial venous thrombosis. Thromb Res. 2015;135(4):673-8.

44. Matsuo T, Kobayashi H, Kario K, Suzuki S. Fibrin D-dimer in thrombogenic disorders. Semin Thromb Hemost. 2000:26(01):101-7.

45. Kogan AE, Mukharyamova KS, Bereznikova AV, Filatov VL, Koshkina EV, Bloshchitsyna MN, Katrukha AG. Monoclonal antibodies with equal specificity to D-dimer and high-molecular-weight fibrin degradation products. Blood Coagul Fibrinolysis. 2016;27(5):542-50.

46. Urbach $\mathrm{H}$, Hartmann A, Pohl C, Omran H, Wilhelm K, Flacke S, Schild H, Klockgether T. Local intra-arterial thrombolysis in the carotid territory: does recanalization depend on the thromboembolus type? Neuroradiology. 2002; 44(8):695-9.

47. Shorr AF, Thomas SJ, Alkins SA, Fitzpatrick TM, Ling GS. D-dimer Correlates With Proinflammatory Cytokine Levels and Outcomes in Critically III Patients. Chest. 2002;121(4):1262-8.

48. Robson SC, Shephard EG, Kirsch RE. Fibrin degradation product D-dimer induces the synthesis and release of biologically active $\mathrm{IL}-1 \beta, \mathrm{IL}-6$ and plasminogen activator inhibitors from monocytes in vitro. Br J Haematol. 1994;86(2):322-6.

49. Castellanos M, Castillo J, García MM, Leira R, Serena J, Chamorro A, Dávalos A. Inflammation-Mediated Damage in Progressing Lacunar Infarctions. Stroke. 2002:33(4):982-7.

\section{Publisher's Note}

Springer Nature remains neutral with regard to jurisdictional claims in published maps and institutional affiliations.

Ready to submit your research? Choose BMC and benefit from

- fast, convenient online submission

- thorough peer review by experienced researchers in your field

- rapid publication on acceptance

- support for research data, including large and complex data types

- gold Open Access which fosters wider collaboration and increased citations

- maximum visibility for your research: over $100 \mathrm{M}$ website views per year

At $\mathrm{BMC}$, research is always in progress.

Learn more biomedcentral.com/submissions 